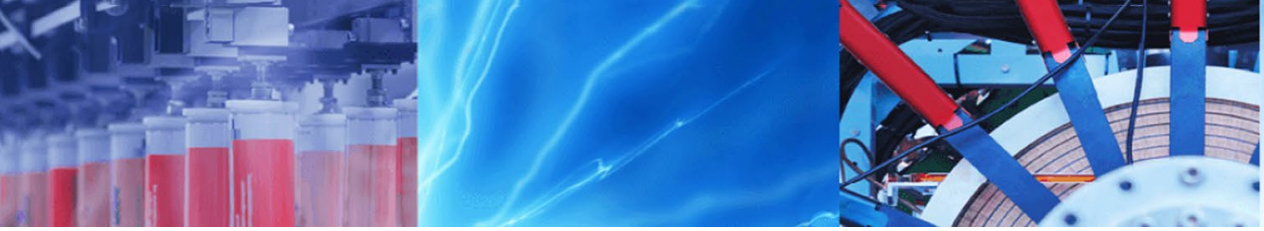

Research Article

\title{
Design and implementation of secured power grid system with information and communication technology
}

\author{
Hasan A. M. Abobaker ${ }^{1}$ (D) . Jan Genci ${ }^{1} \cdot$ Maria Gamcova $^{1} \cdot$ Godem Ali M. Ismeal ${ }^{2}$
}

Received: 4 February 2020 / Accepted: 1 November 2020 / Published online: 19 November 2020

(c) Springer Nature Switzerland AG 2020

\begin{abstract}
This study presents a novel power grid system, for monitoring and controlling a power grid that is made up of various power sources, by using Information and Communication Technologies ICT. This can be hugely contributed to improving the reliability, efficiency as well as towards making smart and automated power systems. The current model was developed in the MATLAB Simulink environment. The proposed system consists of a PV panel, battery, power grid, ICT system/controller, and loads. There are four insulated-gate bipolar transistor switches; namely, IGBT to control battery charging/discharging status and to connect or disconnect either PV panel power source or grid power source depending on the load. The main aim of this model is to develop and implement a grid-connected system that is integrated with PV panel and battery in MATLAB to analyze various operations modes, which include the performance of the PV panel and battery during both the online and offline modes of operation.

The proposed system is said to be capable to monitor and control different power sources, which in turn will lead not only to reducing dependence on non-renewable energies but also to increasing dependence on renewable energies. The simulation results were illustrated and demonstrated that the proposed system can monitor and control the power generated and transmission in real-time in a better and secure manner. On the other hand, exploiting this model leads to reduce the power production costs, creating a clean environment, and also to preserve long term battery life.
\end{abstract}

Keywords Smart grid · Access control · Energy storage $\cdot$ Renewable energy $\cdot$ Information and Communication Technology

\section{Introduction}

Smart grids have received lots of attention in recent times since it is more advanced than the traditional grid systems and it is expected to develop at a rapid rate shortly. Smarter grids will be dependent upon the deployment of Information and Communication Technology (ICT) for supporting better communication and controlling features [1, 2]. A Smart grid contributes to generating the power with optimized energy, and it maintains its voltage, power factor, and the frequencies are automatically obtained based on feedback, which is accomplished from numerous points of the smart grid [3]. Furthermore, it provides universal access to low carbon, affordable power generation, and storage. The grid is generally a non-smart entity that carries out power distribution operations; transmission lines are regulated from the time they are manufactured to the time custom is made. This increase in the current grid system's requirement leads to failure rate, and it will lead to a significant increase in peak load hours [4-6], resulting in extra spending of money. So, there is a need for the

\footnotetext{
$\triangle$ Hasan A. M. Abobaker, atayeib@yahoo.com; Jan Genci, jan.genci@tuke.sk; Maria Gamcova, maria.gamcova@tuke.sk; Godem Ali M. Ismeal, aligodem@gmail.com | ${ }^{1}$ Faculty of Engineering and Informatics, Technical University of Kosice, 04001 Kosice, Slovakia. ${ }^{2}$ College of Electronic Technology Bani Walid, Bani Waled, Libya.
} 
development of self-regulating, fully reliable, and efficient grids. Such systems can incorporate renewable energy generators, which decrease dependence on fossil fuels and thus create an environmentally friendly alternative [7]. ICT is a collective name for different devices that are used for communication of applications used for information technology. In smart grids, they are responsible for the effective communication between different portions of the grid. Recently and due to improvement in technology, the use of ICT has been increasing in all applications. For the last few years, ICT is being implemented in all types of domains especially in communication systems [8]. The integration of conventional power with ICT devices enables real-time communication in two ways. The role of the ICT is to control and communicate with various elements of the smart grids like power generation, renewable sources, customers, distribution and transmission systems, etc. to manage the smart grid, it is necessary to monitor the power system in real-time. The monitored data is communicated with a central system that will be able to control the entire system [9] in the future, there will be multiple advantages of smart grids compared to the conventional grid still used today. The efficiency of electricity generation, distribution, consumption will be improved and will also improve the effectiveness of managing the grid and integrating the renewable sources with grid. Currently, there are separate corridors for transferring renewable sources over long distances due to complexity and lesser efficiency in integration $[2,10,11]$. Since this is costly and requires lots of resources to set up, it is more economical to integrate all power sources into a single grid, since it will save lots of additional equipment and wastage.

The grid is evolving into a more intelligent grid system and this improves the performance of the grid thereby improving the efficiency. In the future, the ICT devices will automatically make decisions based on their sensing capabilities and will control the power that is distributed in a region. However, it will require human intervention to a certain level since it would be difficult to depend entirely on machines. The processed and obtained data in the smart grid are heterogeneous since it has inherent characteristics [12]. The ICT devices play a great role in bringing, monitoring, analyzing, and responding to the problems in the smart grids. The cost of energy, with and without ICT devices like smart meters and other equipment, has been studied in [13]. A model of Vienna has been built and all life cycle phases have been considered for obtaining the parameters and validating the results Along with that, the impact of the lifetime of the components and different implementations have been shown. The impact on the environment when more ICT devices are added has also been presented efficiently by utilizing a holistic technique using an exergy-based life cycle assessment. The obtained results can be used for better integration of smart grids in the future and better production and distribution.

ICTs are getting more important due to the implementation of smart cities and prototypes of smart grids, The device is able to handle data and information available in the network and can communicate using wireless communication or through the Internet of Things (IOT). The available problems in the presently available ICT devices are that it is difficult to connect these devices to all end users like the primary consumers. Various services have to be combined in these devices for better enhancement provides better results. Hence, radical changes are necessary like better infrastructure so that the services will able to reach the consumers immediately, whenever required [14].

A smart grid type infrastructure has been created for small scale smart cities and smart volatile infrastructures in [15], and is called Ipsum. ICT devices may have different types of hardware, software and other intelligence techniques and hence may be costly for consumer use in today's time. The main purpose of Ipsum is to create a smart, powerful and cheap ICT device so that it can be accessible to everyone. The device can be collaborated with different hardware and can perform complex methodologies.

An Anomaly Behaviour Analysis (ABA) has been presented in [16], for detecting and categorizing different situations where faults occur in the smart grid. This technique has been tested against normal operations and also during cyber-attacks. The ABA methodology has been applied for a smart phasor measurement unit for analyzing, identifying, and categorizing the different features of the smart grid. It has been seen that the proposed technique can detect the threats in both smart grids and conventional grids with better detection rates and lower FAR.

A secure power grid must have controlling capabilities and monitoring techniques in the system right from the generation station to the consumers. The communication network may have different hierarchies like local area networks or wide area networks [17]. The local area network connects to the grid using smart meters and enables the communication of end-user to the grid. These multiple local area networks get combined to form a wide area network which includes monitoring devices and distribution stations. These communication networks have different ranges and hence they are all interconnected, the required information may reach the targeted destination quickly. The bandwidth of the communication networks also changes depending upon the communication network. Since there are lots of communication devices required, the cost of installing and maintain these networks may be very high [18]. Power line communications (PLC) and wireless communication will be better suited for 
communication technologies since it has the advantage of getting connected to a large number of devices easily without any additional cost for wiring. However, they also have limitations, where the bandwidth is less, and the distance of transmission is low for the wireless network. There are also security problems associated with it. Therefore, the wireless transmission may be used in local area networks, but will not be used in wide area networks [19].

The requirements for transmitting the data in the grid include reliability, latency, and rate of transmission. This transmitting rate is used to determine the amount of data, which may be transmitted using the communication network within a specific amount of time. The time taken for data to reach the destination correctly is referred to as latency. The measure through which the received data is perceived to be correct is known as reliability. The monitoring technique consists of SCADA, RTU, MTU, etc. SCADA is one of the major devices used in automation in the traditional electricity grid. Remote Terminal Units (RTU) is used to collect the data on the status of the system and initiate different commands. Similarly, Master Terminal Units (MTU) is present that obtains data from a group of RTU, this data is processed and fed into the SCADA system, where appropriate control is taken [20] other control techniques can control the communication network. However, these systems are not able to fulfill the requirements due to inefficient awareness on the situation for the operators and this makes them aware of the disturbances in the neighboring control area and hence, it will be difficult to stop the spread of disturbances [21,22], To solve this problem, updated SCADA systems are used for Advanced Monitoring and Control (AMC), where higher data acquisition rate is prevalent so that a larger data can be obtained to make a better decision and control. More advanced measurements like a vibration in the transmission line and temperature [23] of the transformers [24] are required for better monitoring, thereby data will be generated and sent over the network for a stipulated time limit.

While a smart grid distributes power efficiently, it also requires multiple sources to distribute power efficiently. Renewable sources like PV can be integrated with the grid for efficient usage whenever solar power is available. Although, Renewable energy has been deemed as a vital key in contributing to modern society. But, there is a hugely challenging task in terms of their incorporation to the smart gird. One key and crucial aspect related to the integration of renewable energy is the power factor. There are many concerns linked to the power factor; these include, the variations of both voltage and frequency that are happened due to the difficulty of controlling the variability of renewable energy resources and also harmonics that is produced because of power electronic devices, which is exploited in the renewable energy generation. In short, the effect of such harmonics can be considered as "major" as soon as the renewable energy level of penetration is high.

Also, batteries can be integrated in the circuit to charge and discharge whenever required. A novel dual input boost converter has been designed and created in [25], for integrating the photovoltaic and batter efficiently in a single converter, four different DC-DC converters have been considered for analyzing the circuit. From the results, it has been observed that the converter with the least number of components and the lowest current ripple has been identified and proposed for the grid-connected photovoltaic system. The modes of operations for the proposed converter have been discussed and the method of modeling of the circuit has been discussed. The performance of the proposed circuit was analyzed in detail using MATLAB Simulink. The proposed converter contains multiple voltage doublers that boost the voltage to a high value. Finally, the PI controller has been used for closed-loop operation. This ensures that the output voltage is maintained in the same order.

To the best of our knowledge, this is the first study of its kind presenting a novel power grid system, for monitoring and controlling to integrate power grid with renewable sources on wide area network, by using Information and Communication Technologies ICT, but, some similar previous investigations to the current work have been reported in $[26,27]$. The work in [26] presents the supervision of a PV system with storage connected to the power line and design of a battery protection system. The objective of this article is to manage the charging and discharging of the batteries, taking into account their protection against overload and under load and supervise the system. The novelty of his work to use MATLAB language to drive the Arduino card (AC).

This study involved a PV and battery connected to the BT network. The monitoring algorithm implemented on the Arduino card properly responds to different modes of operation. This is what has allowed the card to ensure both energy management. The study in [27] presents a MATLAB Simulink of PV system with battery storage using a bidirectional DC-DC converter. The Incremental Conductance $(\operatorname{InC})$ algorithm was chosen to be used to track the maximum power point of the solar panel because it provides the optimal duty cycle to generate the PWM signals for the switching devices of the DC-DC converter stage. The main aim of this work is to model and analyze a photovoltaic system coupled with battery energy storage systems using bidirectional DC-DC converters. The overall model has been successfully simulated in Matlab Simulink and satisfactory simulation results have also been obtained.

However, the previous investigations models presented in $[26,27]$ may not be able to monitor and control the 
power sources in a wide area network, both studies have used switch relays, which are convenient only when power grids have low currents, micro-grid with low voltage as an example. Moreover, such work proposed approaches to only make the PV controlling the battery charge.

Thus, in this work, a novel model was developed in MATLAB Simulink environment. The main aim of this model is to develop and implement a power grid-connected system that is integrated with PV panel and battery in MATLAB to analyze various operations which include the performance of the PV panel and Battery during the online and offline modes of operations.

The organization of this paper is as follows: the introduction is presented in Sect. 1, the methodology is given in Sect. 2, the results of the present work are illustrated and demonstrated in Sect. 3, the discussion of the obtained results is placed in Sect. 4, and finally in Sect. 5 the conclusion is given.

\section{Methodology}

In recent times, few researchers have suggested using ICT to integrate renewable power sources with the power grid for monitoring, controlling, protecting, and optimizing the power grid control and its reliability using a scattered control system. When ICT is integrated into the power grid, the transmission becomes more efficient, reliable and safe, and the power delivery becomes more reliable. This improves the benefits by initiating remote monitoring, control, and remote processing. It also allows the users to interact with the power grid thereby improving the delivery of power and customer service.

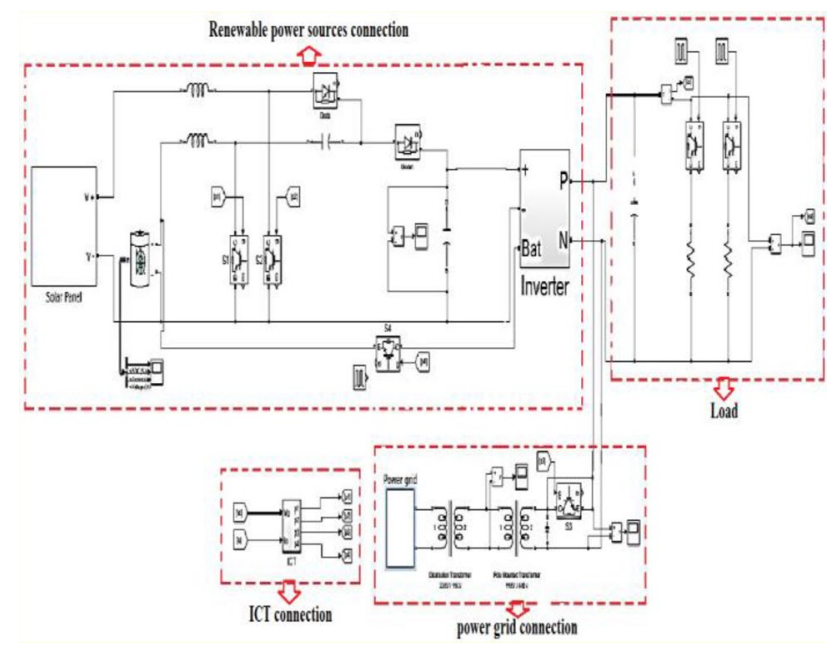

Fig. 1 Proposed system model

\subsection{Overview of the proposed model}

Figure 1 Depicts the Simulink model of the proposed system and it consists of major blocks, which include a block of the power grid connection, a block of the renewable power sources connection, a block of the ICT connection, and the load, the main parameters of the proposed model as shown in Table 1

The block of power grid connection used in the proposed model is shown in Fig. 2, where the voltage is stepped up at the generation side using an $11 / 33 \mathrm{Kv}$ distribution transformer and stepped down in the substation using a $33 / 11 \mathrm{Kv}$ distribution transformer, and further stepped down to $440 \mathrm{~V}$ through a pole-mounted transformer. Since only a single-phase load is considered, $230 \mathrm{~V}$ is obtained from the grid. A Three-phase smart meter installed at the substation to measure the energy consumed and continuously send it to the control unit using a communication model. Depending on the status of the load, the Control unit will send a firing pulse signal to IGBT switch S3 placed at this end to connect/disconnect the power grid, status 1 for connecting, and status 0 for a disconnect. This switch can isolate the grid from the circuit when the PV panels and the battery have sufficient power to supply the load. Three statues of the load was considered in our model, 100,50 , and $33 \Omega$.

Figure 3 demonstrates the renewable power source connection block used in the proposed model, The PV

Table 1 specification of system parametric

\begin{tabular}{ll}
\hline Parameters & Value \\
\hline Grid voltage & $230 \mathrm{v}$ \\
Frequency & $50 \mathrm{~Hz}$ \\
Switching frequency & $10 \mathrm{kHz}$ \\
Transformers & $11 \mathrm{kV} / 33 \mathrm{kV}$ \\
& $33 \mathrm{kV} / 11 \mathrm{kV}$ \\
& $11 \mathrm{kV} / 440 \mathrm{~V}$ \\
DC link voltage & $48 \mathrm{~V}, 196 \mathrm{~V}$ \\
\hline
\end{tabular}

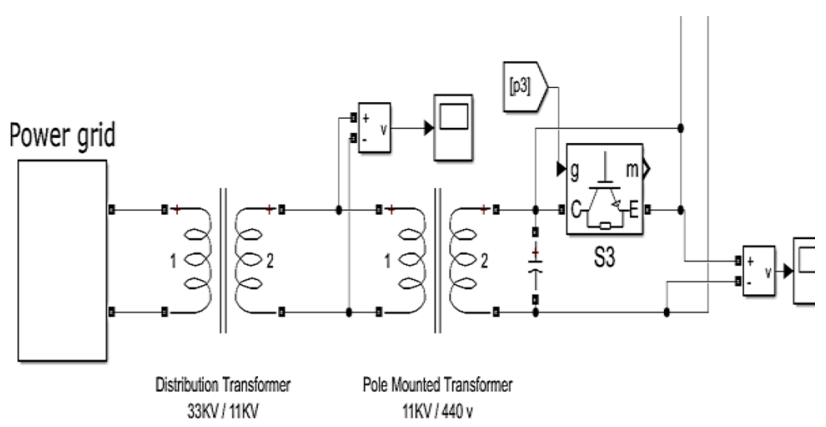

Fig. 2 Block of power grid connection 


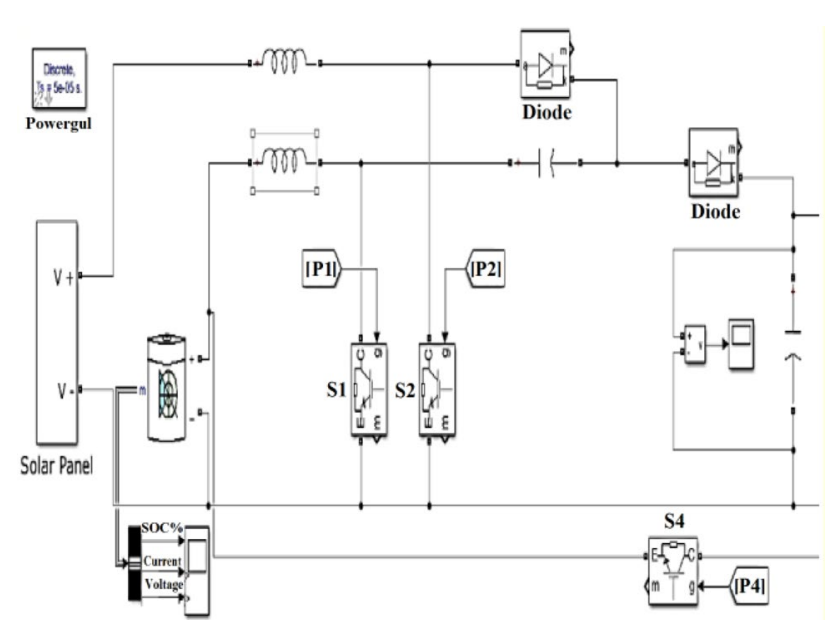

Fig. 3 Block of renewable power sources connection

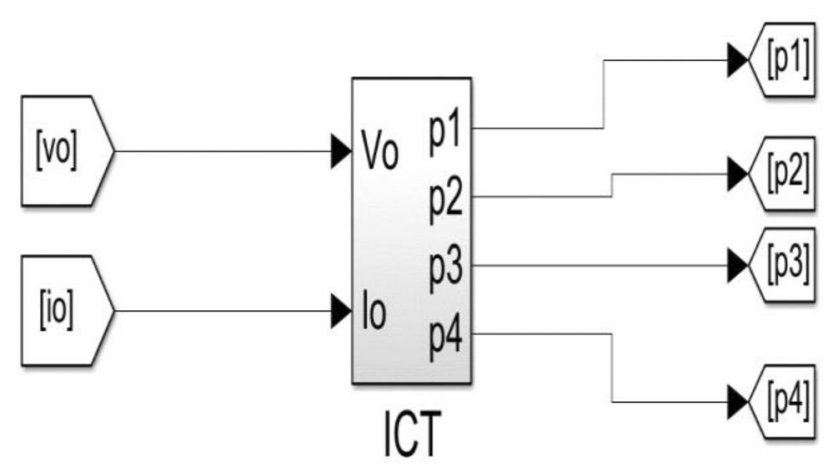

Fig. 4 Block of ICT connection

panel and battery both $48 \mathrm{~V}$ and used as a renewable power source, and connected to a Bi-directional converter that can boost the voltage to four times of the input value to get $196 \mathrm{v} \mathrm{DC}$. This converter has been chosen because it has a high boost ratio with a comparatively lower number of components. Three IGBT switches S1, S2 and S4 are used to control the power of the boost converter, $\mathrm{S} 1$ for battery control in discharge mode when supplying the load, S2 to control the PV voltage, and S4 to control battery charging from the power grid. The three switches are controlled by firing pulse signals from the control unit using the communication model. Bi-directional DC/AC inverter placed at this end.

For effective communication between the different circuits and to control them, an ICT system/controller is used to continuously measuring the voltage and current from different regions, the measured data can be received by control unit using communication model. And the control commands can be send as firing pulse signal to controls the four IGBT switches. Block of the ICT connection is shown in Fig. 4.

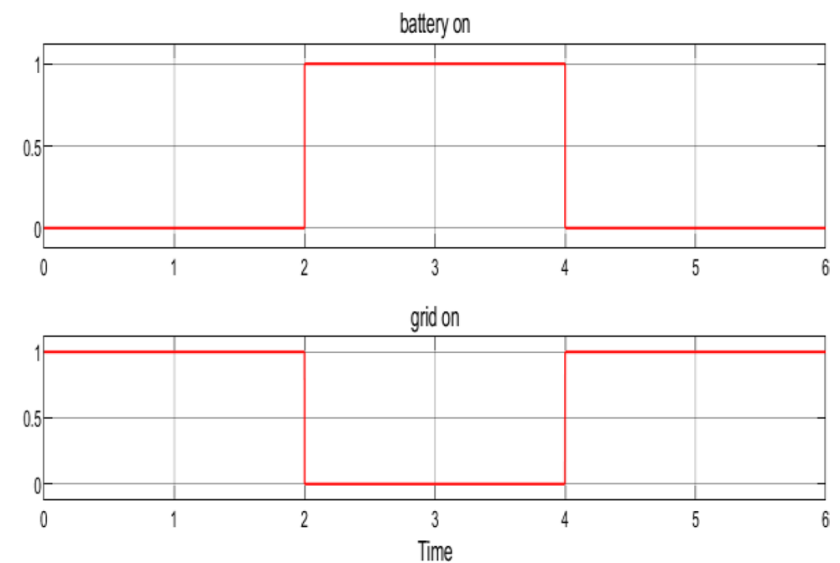

Fig. 5 ON and OFF period of grid and battery

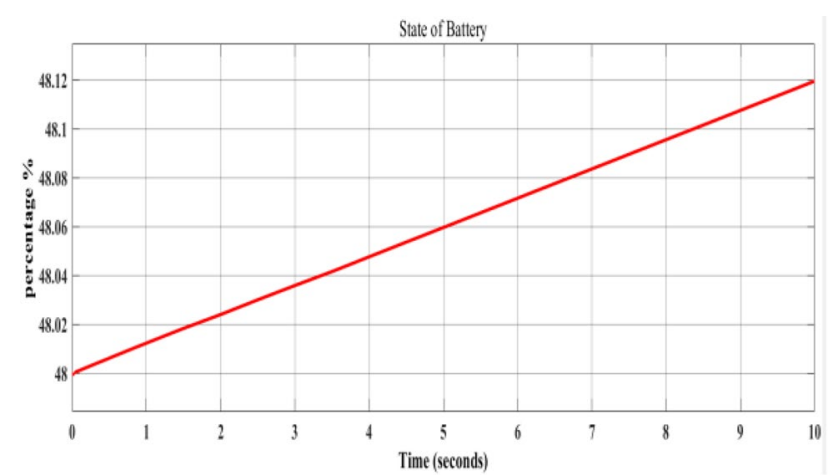

Fig. 6 Battery SOC during charging

\section{Results}

The proposed system with ICT measurement/controller has been simulated using MATLAB-Simulink. The performance of the PV panel, Power fluctuation, battery efficiency, Peak power harvesting period of the PV panel and other parameters can be obtained by running the simulation.

Figure 5 illustrates the ON and OFF period of grid and battery with respect to the switching conditions. The figure shows that when the battery is in ON the voltage across the grid is zero and vice versa.

Figure 6 gives the state of charge of the battery during the charging mode. It can be seen that the voltage is increasing gradually during the battery charging.

Similarly, when there is no enough sunlight, the PV panels would not work and hence the load will be supplied only by the battery. During this mode, the state of charge in the battery will be reduced as seen in Fig. 7 . 


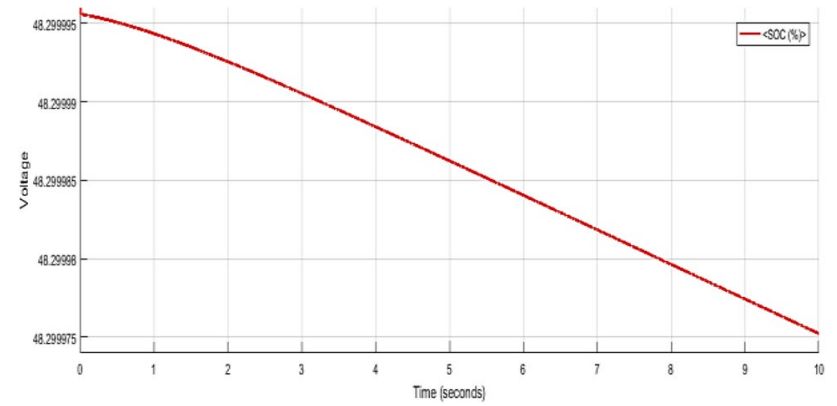

Fig. 7 Battery SOC during discharging

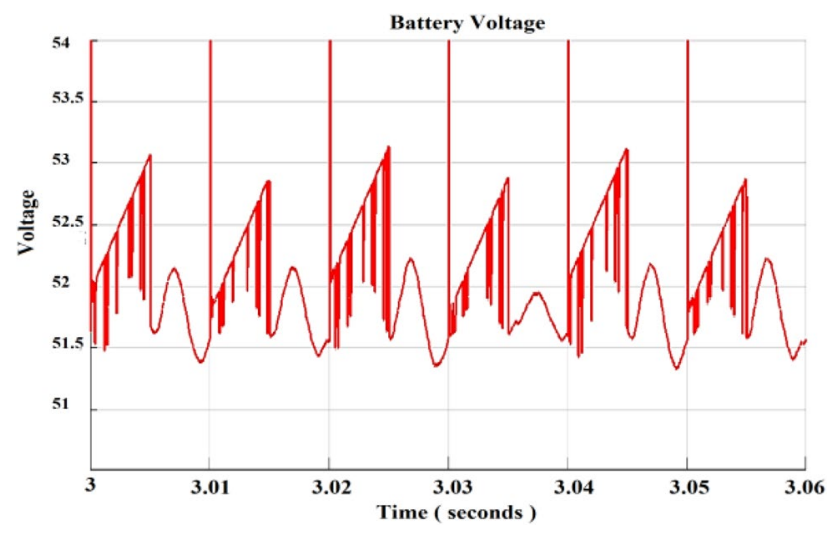

Fig. 8 Battery voltage

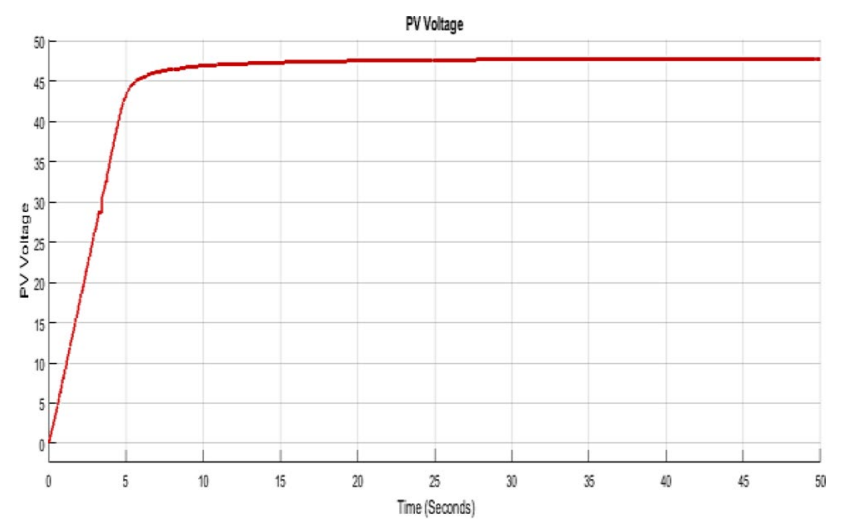

Fig. 9 PV voltage

The battery voltage is seen in Fig. 8. Since it is in charging mode, the battery voltage is slightly higher than the rated voltage. The rated voltage is $48 \mathrm{~V}$, whereas the battery voltage in the charging mode is around $52 \mathrm{~V}$.

The output of the PV voltage before reaching the converter is shown in Fig. 9. It rises from an initial value of zero and starts to increase rapidly and reaches the target voltage within $5 \mathrm{~s}$.
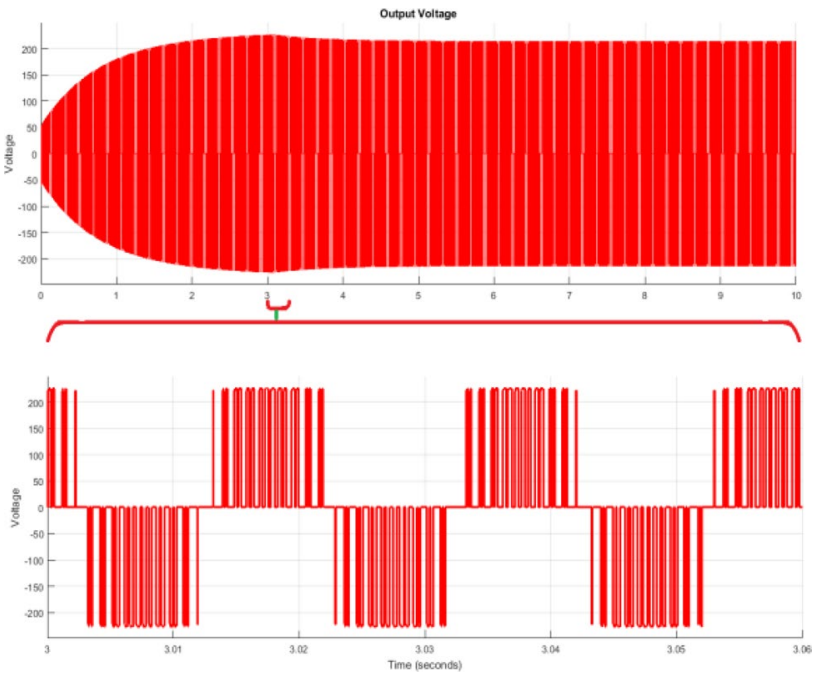

Fig. 10 Output voltage
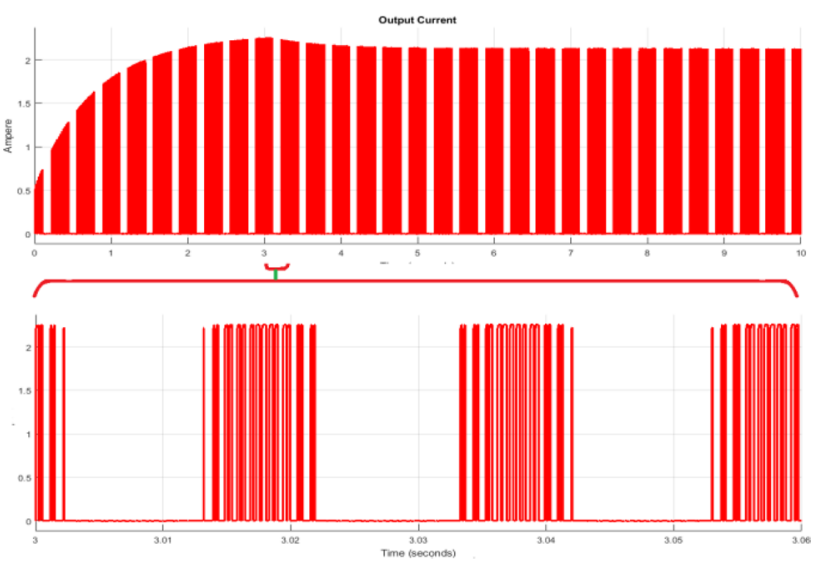

Fig. 11 Output current

The output voltages that are obtained from the load is shown in Fig. 10. The voltage is sinusoidal through pulse width modulation with an amplitude of $230 \mathrm{~V}$. A sample area is zoomed to show the voltage waveforms in the region.

The output current that is consumed by the load is shown in Fig. 11. The current is positive and has a sinusoidal waveform through pulse width modulation with an amplitude of 2.2A. A sample area is zoomed to show the current waveforms in the region.

A three-phase transformer of the range $11 \mathrm{kv}$ is connected to RLC element circuitry to obtain voltage and current inappropriate response. These are the elements comprised in the power grid block and the waveform Fig. 12 depicts the primary and secondary side voltage and current of the grid. 

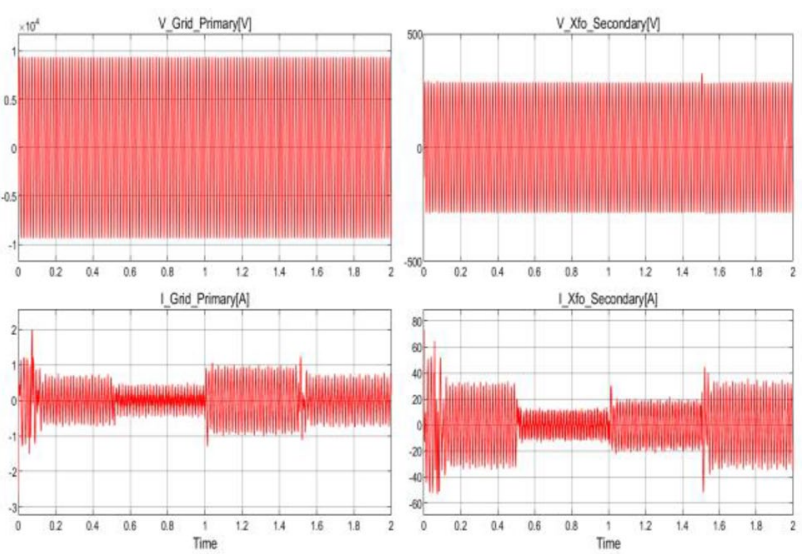

Fig. 12 GRID voltage (V) and current (A)

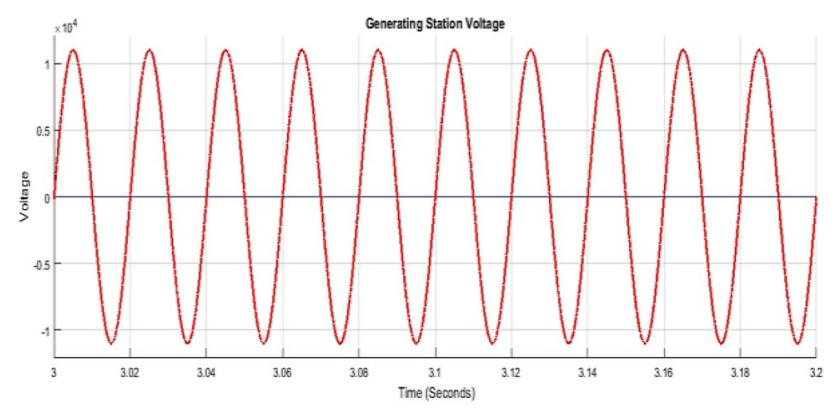

Fig. 13 The voltage at the generating station

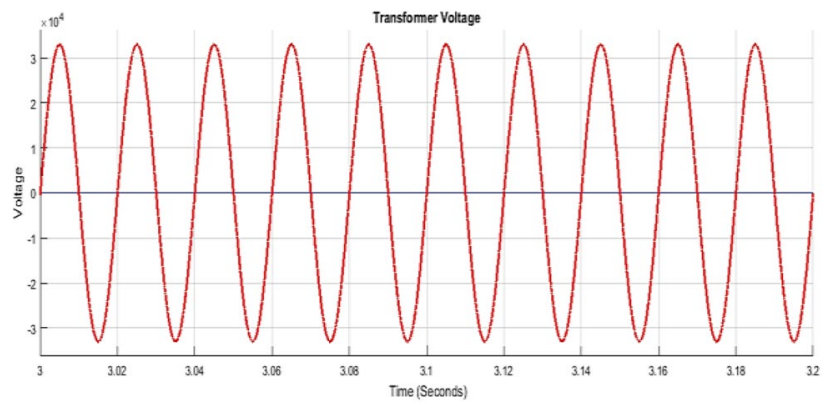

Fig. 14 Transmission voltage

The grid voltages from the generating station, transmission voltage, and the receiving end voltage are shown in Figs. 13, 14, and 15 respectively.

\section{Discussion}

In this study a novel model has been developed in MATLB Simulink to control various power sources, the novelty of this model comes from integrating the ICT with the

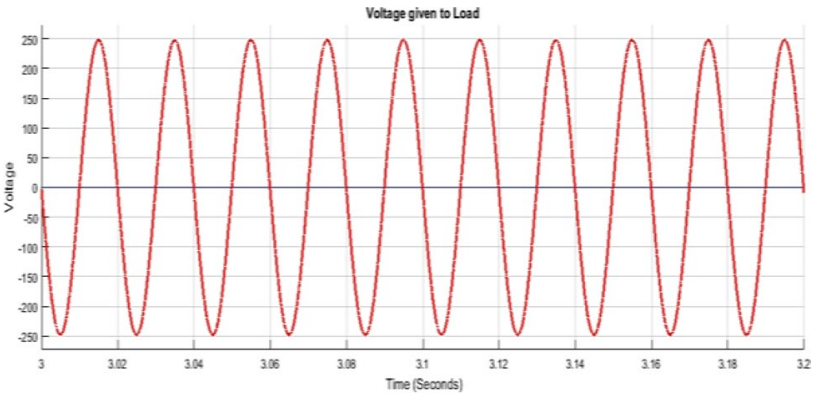

Fig. 15 Grid voltage supplied to the load

power grid and using a special mechanism to monitor various power sources and control them depending on the load consumption using four IGBT switches.

Comparing with the previous studied models proposed in [25-27], our model is more compatible for monitoring and controlling power sources in wide area network, this can help in monitoring and controlling the power system even when the sources are far from each other, moreover IGBT switch can cut the power lines even with high current, but the switch relays that were exploited in [25-27] are only useful when power grids have low currents, micro-grid with low voltage as an example, furthermore, in those proposed findings the PV only controlled the battery charge, However, within this work, we improved this issue by adding IGBT switch to charge the battery from the power grid when is needed, ICTs make our model as a part of the grid system, which controls all power grid and not only isolated solution to control part of the grid.

\subsection{Evaluation of battery charging capacity}

SOC in battery id the amount of the current it can supply after the complete charging limit. Standard SOC values ranges between 0 and 1 . When SOC value is 0 , then the battery is said to be drained and if it goes under the limit then it will damage the store device.

In this work, the battery is maintained at $50 \%$ state of charge at the initial stage and it gets charged whenever the grid is ON, (i.e) S3 and S4 is ON. Similarly, when the load is low, the PV and battery are enough to compensate the load. Hence, there won't be any power consumption from the grid. In this step, the switches S1 and $\mathrm{S} 2$ will be $\mathrm{ON}$ and the battery will be in discharging mode. The battery charging and discharging along with the current is shown in Fig. 16 and compared with the status of the four switches. 


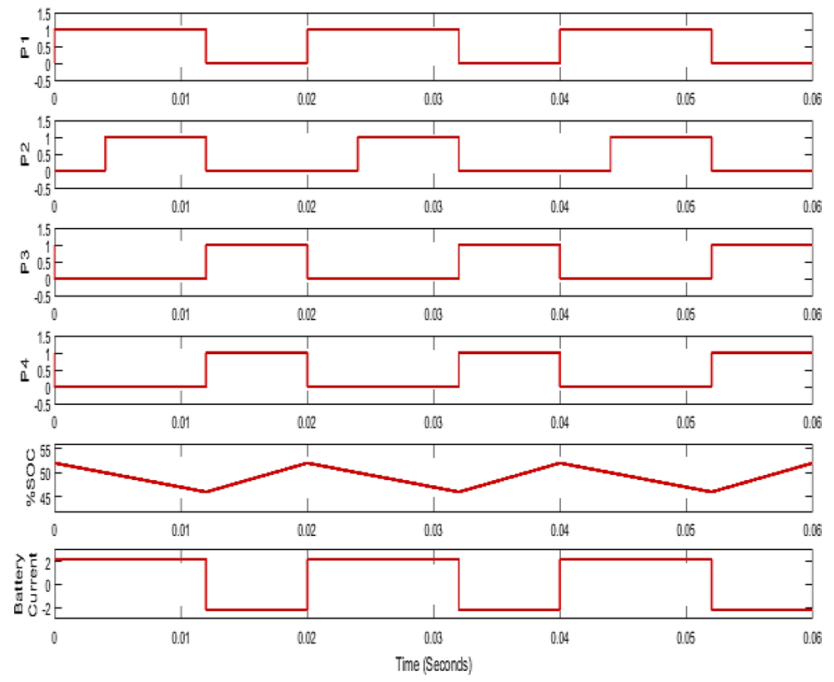

Fig. 16 Pulse for the switches and the corresponding battery parameters

\subsection{Steady-state operation}

The steady-state operation of the proposed system was analyzed to monitor the smooth transfer of power to endusers and also to display the operation of the three-phase converter at both ends such as $A C$ and $D C$ voltage ports. The input voltage is $210 \mathrm{~V}$ and the load power of $3.4 \mathrm{KW}$, the voltage at the $D C$ port is $18 \mathrm{~V}$ and low at $A C$ port is $9 \mathrm{~V}$. The input current and voltage are in phase which in turn indicates the operation of unity power factor. Further, the $D C$ bus voltage is regulated at $12 \mathrm{v}$ and the $A C$ bus voltage is regulated at $230 \mathrm{~V}$, hence high-quality voltage will be generated for utilities.

\subsection{Line regulation}

The input voltage does not remain constant due to the variation of PV, battery, and grid sources. In spite of this, the output voltage has to remain constant since it is very important for network stability. Line regulation is important since it is necessary to maintain a constant voltage even when there is variation in the input. The output from the PV should be $48 \mathrm{v}$; however, the voltage may change based on the availability of sunlight. This DC power is converted to $A C$ power and a small variation in the $D C$ power might affect the boosted AC voltage. Despite this, the output voltage remains constant as seen in Fig. 10 at a constant voltage of $230 \mathrm{~V}$.

\subsection{Load regulation}

The load may not be constant since the requirement of the load may change according to the time. However, the
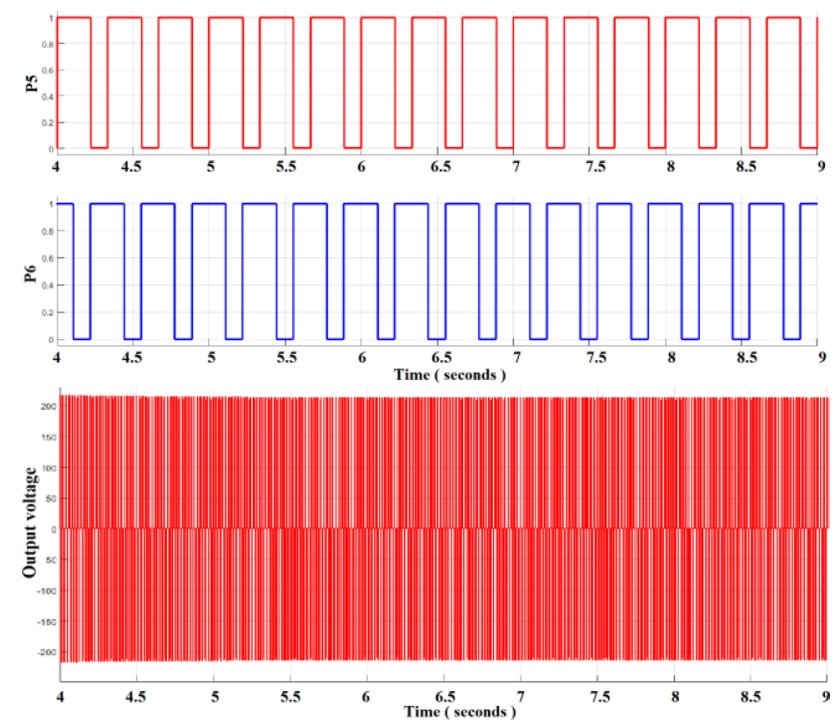

Fig. 17 Load regulation

voltage has to remain constant despite the changes in the load. Load Regulation is important since it is necessary to maintain a constant voltage even when there is variation in the load. The load has been changed in this study by using two different loads to create the effect of three different loads. The loads used in this study are 50 and $100 \Omega$ and controlled by two switches S5 and S6. When both these switches are switched ON, the effective resistance is $33.33 \Omega$ which signifies a different load. The setup of the switches can be seen in the proposed model in Fig. 1. The loads are altered between each other as shown in Fig. 17. It can be seen from the figure that the output voltage remains constant despite changes in the output load at a constant voltage of $230 \mathrm{~V}$.

\section{Conclusion}

This paper has proposed a methodology to integrate the power grid with ICT to monitor and control the effective power transmission and also to detect early fault occurrence by regular observation of the load's behavior. Particularly, it helps in reducing the physical damage to the component present in the power system, since it monitors the self-healing time it takes to remove from the sudden breakdown or disturbance. The simulation was done for three types of loads to analyze the performance of the power system and the results obtained show the voltage and current waveform of the PV panel and battery. The state of charge (SOC) indicates that it correct the error in voltage discharge of the battery and the steady-state analysis indicates the smooth power transfer between the load and electrical substation. Finally, the proposed 
methodology is considered to be suitable for smart monitoring and controlling of power transmission. Apart from this research, it also focuses on predicting the fault occurrence. The future work focuses on implementing the same in the practical power system with reduced installation cost and the power loss in order to make the system more reliable and secured.

\section{Compliance with ethical standards}

Conflict of interest The authors declare that they have no conflict of interest.

\section{References}

1. Hahn A, Ashok A, Sridhar S, Govindarasu M (2013) Cyber-physical security testbeds: architecture, application, and evaluation for smart grid. IEEE Trans Smart Grid 4(2):847-855

2. Feltes JW, Gemmell BD, Retzmann D (2011) From smart grid to super grid: solutions with HVDC and FACTS for grid access of renewable energy sources. In: 2011 IEEE power and energy society general meeting, pp 1-6

3. Cárdenas A, Safavi-Naini R (2012) Security and privacy in the smart grid. In: Handbook on securing cyber-physical critical infrastructure. Elsevier, pp 637-654

4. Nayan F, Islam MA, Mahmud S (2013) Feasibility study of smart grid in Bangladesh. Energy Power Eng 05(04):1531-1535

5. Ourahou M, Ayrir W, Hassouni BEL, Haddi A (2020) Review on smart grid control and reliability in presence of renewable energies: Challenges and prospects. Math Comput Simul 167:19-31

6. Hashmi M, Hanninen S, Maki K (2011) Survey of smart grid concepts, architectures, and technological demonstrations worldwide. In: 2011 IEEE PES conference on innovative smart grid technologies Latin America (ISGT LA), pp 1-7

7. Irfan M, Iqbal J, Iqbal A, Iqbal Z, Riaz RA, Mehmood A (2017) Opportunities and challenges in control of smart grids - Pakistani perspective. Renew Sust Energ Rev 71:652-674

8. Tøndel IA, Foros J, Kilskar SS, Hokstad P, Jaatun MG (2018) Interdependencies and reliability in the combined ICT and power system: an overview of current research. Appl Comput Inform 14(1):17-27

9. Leszczyna R (2018) A review of standards with cybersecurity requirements for smart grid. Comput Secur 77:262-276

10. Loureiro MV, Schell KR, Claro J, Fischbeck P (2018) Renewable integration through transmission network expansion planning under uncertainty. Electr Power Syst Res 165:45-52

11. Iqbal MM, Islam K (2017) Design and simulation of A PV system with battery storage using bidirectional Dc-Dc converter using matlab simulink. Int J Sci Technol Res 6(07) ISSN 2277-8616 403

12. Sanchez-Hidalgo M-A, Cano M-D (2018) A survey on visual data representation for smart grids control and monitoring. Sustain Energ Grids Netw 16:351-369
13. Aleksic S, Mujan V (2018) Exergy cost of information and communication equipment for smart metering and smart grids. Sustain Energ Grids Netw 14:1-11

14. Ahmed F, Naeem M, Iqbal M (2017) ICT and renewable energy: a way forward to the next generation telecom base stations. Telecommun Syst 64:43-56. https://doi.org/10.1007/s1123 5-016-0156-4

15. Håkansson A (2018) Ipsum - an approach to smart volatile ICTinfrastructures for smart cities and communities. Proc Comput Sci 126:2107-2116

16. Orozco A, Pacheco J, Hariri S (2017) Anomaly behavior analysis for smart grid automation system. In: 2017 IEEE international autumn meeting on power, electronics and computing (ROPEC), pp. 1-7

17. Berger LT, Iniewski K (2012) Smart grid applications, communications, and security. Wiley, Hoboken, NJ

18. Kayastha N, Niyato D, Hossain E, Han Z (2014) Smart grid sensor data collection, communication, and networking: a tutorial. Wirel Commun Mob Comput 14(11):1055-1087

19. Khan A, Ali M, Ahmad I, Ullah A, Rahman HU, Rahman HU (2012) WIMAX implementation of smart grid wide area power system load protection model in MATLAB/SIMULINK. Smart Grid Renew Energ 3(4):282-293

20. Shahidehpour $M$, Wang $Y$ (2003) Communication and control in electric power systems: applications of parallel and distributed processing. Wiley-IEEE Press

21. Hauser $\mathrm{CH}$, Bakken DE, Bose A (2005) A failure to communicate: next generation communication requirements, technologies, and architecture for the electric power grid. IEEE Power Energ Mag 3(2):47-55

22. Anjia M, Jiaxi Y, Zhizhong G (2005) PMU placement and data processing in WAMS that complements SCADA. In: IEEE power engineering society general meeting, pp 690-693

23. Garcia B, Burgos JC, Alonso A (2006) Transformer tank vibration modeling as a method of detecting winding deformations-part I: theoretical foundation. IEEE Trans Power Deliv 21(1):157-163

24. Pradhan MK (2006) Assessment of the status of insulation during thermal stress accelerated experiments on transformer prototypes. IEEE Trans Dielectr Electr Insul 13(1):227-237

25. Lavanya A, Jayaseelan N, Navamani JD, Kumar KV (2017) Dual input DC-DC converter for renewable energy systems. In: 2017 International conference on inventive systems and control (ICISC), pp 1-5

26. Diahovchenko I, Kolcun M, Čonka Z et al (2020) Progress and challenges in smart grids: distributed generation, smart metering, energy storage and smart loads. Iran J Sci Technol Trans Electr Eng. https://doi.org/10.1007/s40998-020-00322-8

27. Traore $\mathrm{M}$ et al (2018) Supervision of a PV system with storage connected to the power line and design of a battery protection system. Wirel Netw. https://doi.org/10.1007/s11276-018-1886-x

Publisher's Note pringer Nature remains neutral with regard to jurisdictional claims in published maps and institutional affiliations. 